\title{
Junior Secondary Students' Perceptions of Influences on Their Engagement with Schooling
}

\author{
Peter Sullivan \\ Monash University \\ Craig Deed \\ La Trobe University \\ Andrea McDonough \\ Australian Catholic University
}

\author{
Vaughan Prain \\ La Trobe University \\ Sue Drane \\ La Trobe University \\ Angie Mornane \\ Monash University
}

\author{
Chris Campbell \\ The University of Notre Dame \\ Australia \\ Michael Faulkner \\ La Trobe University \\ Caroline Smith \\ Australian Catholic University
}

\begin{abstract}
Various explanations and solutions have been proposed over the last decade in relation to the implications of students' apparent lack of engagement with middle years schooling in Australia. In this article we report on responses to a questionnaire by 333 Year 8 students (aged about 13, the second year of high school) on perceptions of factors relating to their engagement with the academic curriculum. We found that while the majority of students reported a strong sense of the importance of, and opportunities in, schooling, and saw English, mathematics and science connected to those opportunities, this orientation was not matched by corresponding positive engagement with these same subjects. We also found that there was diversity in the responses of students, and recommend that schools take steps to identify individual students' perceptions of factors influencing their engagement, and where appropriate, address those perceptions.
\end{abstract}

\section{Introduction}

There have been sustained attempts over the last decade to explain and address student disengagement in the middle years of schooling (students aged 10 to 14) in Australia. This disengagement has been variously attributed to irrelevant, unchallenging curricula, inappropriate student tasks, ineffectual learning and teaching processes, and changed cultural and technological conditions (see Luke et al., 2003). Other highlighted factors include a combination of students' familial economic resources and cultural capital, and their self attributions with respect to personal achievement (Onyx, Wood, Bullen, \& Osburn, 2005; Taylor \& Nelms, 2008).

We report on some data collection from a project that is investigating factors affecting this disengagement with middle years schooling in a regional setting. The project, titled WHOLE ${ }^{1}$, examines the issue from multiple perspectives, including general pedagogical and social interventions, and well as specific initiatives in the key curriculum areas of English, mathematics and science. The project is being undertaken in three schools in regional Australia: a Catholic regional secondary college (CRC), a government secondary college (GSC) in the same regional city, and a small rural Catholic secondary College (St X). These schools volunteered to participate because of a specific intention to improve the level of engagement of their students. The two regional city schools serve predominantly lower socio-economic families, and the rural school combines a small town and rural student enrolment. There are two themes in the project: some of us are working with teachers on general interventions to increase the students' awareness of and ability to self-regulate; and others are working on pedagogical approaches in English, mathematics and science designed to increase student decision making. Our project was intended to explore both

\footnotetext{
${ }^{1}$ The WHOLE project is the result of collaboration between three schools, and three universities (Monash, La Trobe and Australian Catholic) and is funded by the Australian Research Council LP 0668937. The views expressed are those of the authors.
} 
attitudinal and aspirational dimensions of student engagement in these regional schools, with the intention of recommending interventions to address the apparent disengagement of students.We present here the results of a questionnaire completed by 333 Year 8 students, reporting on their perceptions of various aspects of their engagement in schooling, on the assumption that this analysis provides part of an emerging basis for planning strategic interventions with their teachers.

Following Fredricks, Blumenfeld, and Paris (2004), we support the view that engagement should be understood as a multi-faceted construct. From this perspective, engagement can be characterised behaviourally (strong participation in academic, social and extra-curricular activities), emotionally (affective ties with teachers, classmates, school, and parents), and cognitively (investment in effort to master complex problems and skills), with overlap across each facet.

While accepting that diverse factors influence student effort at school, we assume, like many other researchers (Ames, 1992; Boekaerts \& Cascallar, 2006; Greene \& Azevedo, 2007; Zimmermann, 2001), that a key element in engaging middle year students is promoting their capacity to self regulate their learning. In surveying the students at the outset of the project, we were interested in their perception of factors influencing their learning, how much, and in what ways, they could set and achieve goals for post-school futures, engage with school subjects, and feel they have influence over their academic success.

\section{Influences on student engagement in the middle years}

Two elements informing this research are the literature on student self-regulation, and some preliminary studies conducted by members of the research team. These are each discussed in the following sections.

\section{Perspectives on student self-regulation}

Many commentators have noted the longstanding student disengagement in learning in the middle years in Australia (e.g., Australian Curriculum Studies Association, 1996; Hunter, 2007; Main \& Bryer, 2007). Two broad explanatory frameworks have been proposed generally to account for this lack of engagement.

The first, drawing predominantly on curricular development and pedagogical theories embedded within a broader context of social change, proposes that a major contributor is inappropriate curricular content for these learners (Apple \& Beane, 1999; Cumming, 1996; Luke et al., 2003; Pendergast et al., 2005). A common recommendation is for students to engage with rich tasks and meaningful activities in an integrated curriculum that focuses on big ideas, rather than piecemeal, segmented, trivial content.

The second framework explains student disengagement in terms of sociocultural and psychological factors, with some researchers seeking to link these factors (e.g., Martin \& Marsh, 2006). One strand within this research, which has shaped our project, focuses on learners' lack of generative adaptive strategies for knowing how to improve their learning (Dweck, 2000; Sullivan, McDonough, \& Prain, 2005; Zimmermann, 2001). Other researchers, such as Delpit (1988), have explained student engagement in terms of sociocultural factors. Delpit (1988) asserted that students might experience discontinuities between the curriculum pedagogy and assessment regimes, and their own culture and family-influenced expectations.

One of our assumptions is that interventions to improve student self-regulation can accommodate the issues in both of these frameworks. Self regulated learning is broadly defined as the use of strategies to achieve academic growth and well-being goals. For Boekaerts (2006), "self-regulation refers to multi-component, iterative, self-steering processes that target one's own cognitions, feelings, and actions, as well as features of the environment for modulation in the service of one's own goals" (p. 1). Pintrich and de Groot (1990) made the compelling point that "student involvement in self-regulated learning is closely tied to students' efficacy beliefs about their 
capability to perform classroom tasks and to their beliefs that these classroom tasks are interesting and worth learning" (p. 38). In summarising this position, and identifying the challenges teachers still face in promoting student self-regulation, Pintrich and de Groot (1990) emphasised that students need to have both the "will" and the "skill" for learning gains to occur (p. 38).

Complementing these perspectives is the work of Ames (1992) and Dweck (2000) who categorised students' orientation to learning in terms of whether they hold either mastery goals or performance goals. Students with mastery goals seek to understand the content, and evaluate their success by whether they feel they can use and transfer their knowledge. They tend to have a resilient response to failure, they remain focused on mastering skills and knowledge even when challenged, they do not see failure as an indictment on themselves, and they believe that effort leads to success. Students with performance goals are interested predominantly in whether they can perform assigned tasks correctly, as defined by the endorsement of the teacher. Such students seek success but mainly on tasks with which they are familiar. They avoid or give up quickly on challenging tasks, they derive their perception of ability from their capacity to attract recognition, and they feel threats to self-worth when effort does not lead to recognition. It is noted that performance goals to please a teacher can motivate students to complete tasks satisfactorily as long as the teacher's endorsement is forthcoming (Elliot, 1999). Such goals can also lead to performance avoidance in which students choose not to engage in tasks for fear of failure and the risk of teacher censure.

Overall, the project is investigating the ways that these various perspectives assist our descriptions of the factors influencing students' engagement in school.

\section{Some preliminary studies informing the emphasis in the research}

In an earlier study, we investigated individual students' perceptions of the extent to which their own efforts contribute to success in mathematics (see Sullivan, Tobias, \& McDonough, 2006) and English (Sullivan, McDonough, \& Prain, 2005) through interviews in which Year 8 students encountered increasingly difficult tasks. The intention was that eventually nearly all students would confront the challenge of a task which was difficult for them. The students were asked how they felt about the challenge they experienced, and the type of support they needed to solve the problem. It was noted that virtually all students persisted in the tasks they were posed, suggesting that the oneon-one interview situation was different from the classroom context. Sullivan and McDonough (2007) conducted some information sessions on the results from the overall questionnaire for a particular Year 8 class and reported that the students showed more confidence in their ability to learn mathematics and in their persistence than observations of their engagement in class indicated was warranted. The students identified a negative influence of peers for some classmates but less for themselves, and had modest career aspirations. In responding to a questionnaire 24 Year 8 teachers at CRC reported that these students demonstrated high levels of disengagement, variously characterised as boredom, lack of confidence, poor attitudes, absenteeism, disruptive behaviour, and lack of understanding of the need to prepare for the future through developing post-school goals (Tadich, Deed, Campbell, \& Prain, 2007). In these latter two studies it was noted that students resisted tasks that were high in cognitive demand for them by threatening classroom order (see Doyle, 1986, and Desforges \& Cockburn, 1987 for extended discussion of this phenomenon). Dweck (2000) argued that students with a performance orientation influenced teachers to pose tasks in which they can succeed.

The WHOLE project, building on the literature and these preliminary studies, aims to identify key influences on students' level of engagement in the early secondary years. Our overall research questions are:

What self-regulatory capacities do students use and what is their approach to learning?

What interventions increase the students' capacity for self-regulation of, and positive approach to, their learning? 
To provide some overall background information for the interventions, we asked students to respond to a questionnaire, the results of which are reported below.

\section{Responses to the student questionnaire}

The data reported below are summaries of students' responses to items addressing issues influencing their self-regulatory capacities. The use of self report Likert scales to gain insights into trends in attitudes and beliefs is common, and is often used to inform more sensitive qualitative investigations and interventions, as is the case here. Our questionnaire was based on the instrument reported by Martin and Marsh (2006) that sought students' responses to items associated with motivation. We removed some of the items and added others similar to those proposed by Dweck (2000) predominantly seeking to explore students' incremental or entity perspectives on intelligence, and items associated with vocational or life aspirations. Overall, our intention was for the instrument to be brief, clear, unambiguous, and individually completed in less than 20 minutes, requiring minimal assistance or explanation. The questionnaire was piloted with similar students to the target population, one on one, with the students speaking aloud as they responded, and changes were made to clarify wording.

The questionnaire consisted of mostly Likert type items, reflecting the structure of the Martin and Marsh survey. As expected, given that they were created from valid and reliable instruments, the items were reliable $(\lambda=0.827)$ and so give readers confidence that the items are reasonable measures of the students' perceptions. Even though the pre-testing indicated that the results were suitable for factor analysis (MSA $=.904)$ it appeared that nearly all items were correlated, and so no distinct factors were identified. Instead, the results for individual items that address similar issues are grouped to allow consideration of the strength and direction of the student responses.

In analysing the data, we recognise that students may be responding to questions to which they have given little prior consideration, may misinterpret questions, may seek to meet teacher expectations in their responses, or may give unreflective "stock" responses. We have addressed these concerns by taking into account a range of evidential sources in our analysis, including our other studies related to the project, and by presenting claims about the relationships between the reported student perceptions and their classroom engagement and behaviour as starting points for further investigation. We also note that there is strong consistency between items, and the trends across the three schools are very similar, further suggesting that the responses overall are a reasonable representation of the views of the students.

\section{The extent to which students connect school learning opportunities to their futures}

One of our assumptions is that students who see school as valuable preparation for employment or other opportunities would actively engage in schooling. Table 1 presents the items related to this connection between school and future opportunities. In addition to the means overall, it presents the comparison between boys and girls, and the means for the respective schools. Note that the scale is 7 point, so a mean of 6 indicates very strong overall agreement with the proposition, and a score of 4 is neutral.

Table 1: Connection between school and future opportunities

\begin{tabular}{|c|c|c|c|c|c|c|}
\hline & $\begin{array}{c}\text { Mean } \\
\mathrm{n}=333\end{array}$ & $\begin{array}{c}\text { Boys } \\
\mathrm{n}=174\end{array}$ & $\begin{array}{c}\text { Girls } \\
\mathrm{n}=159\end{array}$ & $\begin{array}{c}\text { CRC } \\
n=200\end{array}$ & $\begin{array}{c}\text { St } \mathrm{X} \\
\mathrm{n}=23\end{array}$ & $\begin{array}{l}\text { GSC } \\
\mathrm{n}=110\end{array}$ \\
\hline $\begin{array}{l}\text { I am able to use what I learn in school in } \\
\text { other parts of my life }\end{array}$ & 5.08 & 5.02 & 5.14 & 5.19 & 4.61 & 4.96 \\
\hline Learning at school is important & 5.96 & 5.76 & 6.17 & 6.10 & 5.70 & 5.75 \\
\hline $\begin{array}{l}\text { Most of what I learn at school will be } \\
\text { useful to me someday }\end{array}$ & 5.60 & 5.66 & 5.53 & 5.69 & 5.52 & 5.45 \\
\hline
\end{tabular}


It's important to understand what I'm taught at school

Trying hard in English will give me more future job opportunities

Trying hard in science will give me more future job opportunities

Trying hard in maths will give me more future job opportunities
5.75
5.58
5.93
5.90
5.39

5.87

5.78

5.97

5.99

5.65

5.70

5.02

5.16

5.36

4.74

6.16

6.14

6.18

6.28

6.00

5.98

These student responses (on a scale of 1 to 7 ) are all positive, with the responses to the items on trying hard in English and mathematics being very positive, and the items on the importance of learning at school and understanding what they are taught also being positive. The inference would be that these students, overall, would accept that it is important to engage in whatever schools offered them.

In this table, and in most of the following tables, the differences between the responses of girls and boys are not significant. The same is true for the comparisons between the schools. The following tables present only aggregate data.

We are interested in whether there were differences in responses based on student ability. For this, we use the scores on the systemic mathematics, reading, and writing assessments that these students completed when in Year 7 as achievement measures, and for ease of comparing responses of groups, categorise students as within the top third, middle third, and bottom third on the reading and the first of the mathematics assessments. For the items in this table, the top third, the middle third, and bottom third, on both reading and mathematics, gave similar distributions of responses. In other words, the students with high scores on the systemic assessments were no more likely to see school as important and useful, or success as connected to trying hard, than other students.

The challenge in interpreting these results is this. The responses of the students overall do not match with our observations of students in class. We have conducted structured observations of English and mathematics classes and while there were a few disruptive students, the main conclusion is that students overall do not persevere on challenging tasks and the teachers often remove some of the risk by providing additional information, thereby reducing the challenge and the learning opportunities. While it is possible that, in the questionnaire, the students are repeating received ideas about why schooling matters, or that they do not make strong links between a general longterm purpose for their schooling and effort in particular subjects in Year 8, it is also possible that the responses do represent the students' real views, but that something inhibits the enaction of the implied motivations in everyday classrooms. In other words, we interpret this to mean there is little to gain by working to improve students' orientations to learning, and much to gain by improving the ways that classrooms operate.

\section{Possible influences on students' approaches to schoolwork}

Following Dweck's (2000) broad distinction between mastery and performance self-goals, we were also interested in seeking insights into what the students perceived as reasons for trying at school. The items in Table 2 report the students' perceptions of particular factors that may influence them. Given the similarity in distribution between the subgroups, only the mean and standard deviation of the overall responses are presented in subsequent tables.

Table 2: Rating of external influences on the students when working well $(\mathrm{n}=333)$

\begin{tabular}{lcc}
\hline Often the main reason I work at school is because I want people to think that & 2.96 & 1.68 \\
I'm smart & &
\end{tabular}


Often the main reason I work well at school is that I want to please my parents

Often the main reason I work well at school is that the schoolwork interests me

Often ...I work well at school is the personal encouragement of teachers

Often ... I work well at school is the feeling that I am capable of doing it successfully

Noting that a score of 4 is neutral, only the feeling of capability and wanting to please their parents are positive influences for the students overall. The responses indicate that the sense of interest, personal encouragement of teachers, and wanting people to think they are smart, are not positive influences. There were no significant relationships between the responses and the achievement scores in English and mathematics, with the one exception that the top third of students in English were significantly less likely to rate pleasing their parents as a reason for working well (Chi Squared, $d f=12, \mathrm{p}=.004)$.

The responses indicating that the students overall are positive about wanting to please their parents, was confirmed in another item on the questionnaire in which they were asked to rank a set of possibly relevant factors. In this, the highest ranked factors was "I want my parents to be proud of my achievement at school".

These results raise some interesting challenges to conventional views of students. While our study of teacher perspectives (Tadich et al., 2007) indicated that teachers believed they had to make learning interesting and provide encouragement to motivate students, these students rated these factors as slightly below neutral. This could be interpreted in various ways: (a) students do not expect schooling to be interesting; (b) students do not perceive past experiences of subjects as interesting; (c) other factors such as peer interactions are more critical to effort; or (d) making learning interesting is simply less important than other nominated motivations.

\section{Self-perceptions of effort}

We were also interested in the students' self-perceptions of their effort, the results of which are presented in Table 3.

Table 3: Rating of students' perception of their own effort $(\mathrm{n}=333)$

\begin{tabular}{lcc}
\hline & Mean & s.d. \\
\hline Sometimes I don't try hard at schoolwork & 3.68 & 1.5 \\
Sometimes I don't try hard at schoolwork so I have an excuse if I don't & 2.63 & 1.52 \\
do so well & & \\
Each week I'm trying less and less & 2.29 & 1.47 \\
I don't really care about school anymore & 2.58 & 1.71 \\
\hline
\end{tabular}

The first item has just over half of the students disagreeing with the proposition, and for the other items the students disagree strongly. In other words, overall the students report that they try hard, and take an interest in school. This supports the earlier result indicating recognition of the importance of schooling. There were no differences based on English and mathematics achievement, with the exception that the top third of the reading students more strongly disagreed with the proposition that "... so I have an excuse" (Chi squared, $d f=12, \mathrm{p}=.002$ ).

All these responses about self-perceptions of effort imply a positive engagement with school tasks, but these perceptions do not match with our classroom observations, nor with the teachers' reports (see Tadich et al., 2007). This may imply that (a) students have an unrealistically favourable view of the effort required to succeed at school, or (b) that students, based on their experience, perceive that only a modest effort is necessary to meet school demands. This confirms earlier responses in 
which students reported that they are adequately motivated to meet these demands. Again it seems that it is not the students' reported attitudes that are at issue, and it may be that a key action is for students to have experiences that challenge them, and discuss their responses to those challenges.

\section{Incremental and entity view of intelligence}

Dweck's (2000) notion of a mastery orientation aligns with an incremental view of intelligence in which students believe they can enhance their achievement though effort. Students with an entity view believe they are as smart as they will ever get, which aligns with the performance orientation. We were interested in the extent to which students feel that they can improve their success at school tasks through effort, which is associated with an incremental view of intelligence. The responses to the relevant items are presented in Table 4.

Table 4: Rating of influences of other students on effort $(\mathrm{n}=333)$

\begin{tabular}{lcc}
\hline & Mean & s.d. \\
\hline If I try hard, I can do most of my schoolwork well & 5.78 & 1.21 \\
People are either good at school work or not. They cannot get better by & 2.11 & 1.62 \\
trying. & & \\
If I have enough time, I can do well in my schoolwork & 5.61 & 1.39 \\
If I work hard enough, I believe I can get on top of my schoolwork & 5.73 & 1.33 \\
\hline
\end{tabular}

The students responded strongly to the three positive items and strongly rejected the negative item, thus reporting an incremental view of intelligence. These responses represent a strong espousal of their sense of capacity to meet the perceived academic challenges of schooling, with support for the assumption of a strong relationship between amount of effort and success. For most students there is no need to emphasise the connection between effort and success, and it would be better to address other factors that may be constraining effort. There were some students whose responses indicate they have an entity view of their intelligence, and it may be advantageous for teachers to identify such students and work with them on this specifically.

\section{Potential constraining influence of other students}

In our earlier studies we noted that some students, while excluding themselves from this description, considered that some of their classmates did not try because of peer pressure. Table 5 presents the response to items that sought further insights into this potential constraint on student effort.

Table 5: Rating of influences of other students on effort $(\mathrm{n}=333)$

\begin{tabular}{lcc}
\hline & Mean & s.d. \\
\hline In school I try my hardest no matter what the other students say & 4.98 & 1.55 \\
In school I try my hardest no matter what the other students do & 4.97 & 1.46 \\
I put more effort into my schoolwork than most students in my class & 4.28 & 1.45 \\
How hard I work at school depends on what most of the class think or do & 3.20 & 1.54 \\
In my class, ... some students don't try hard because they are afraid of & 5.45 & 1.68 \\
what other people might think & &
\end{tabular}

Given that a score of 5 can be taken as "slightly agree", the students present a qualified agreement that they try their hardest, irrespective of what other students say and do, and they slightly disagree that their effort is dependent on the rest of the class. They do think that some other students are influenced in this way. 
These responses confirm the result from the earlier studies that students deny that other students influence their own effort, but do identify this as a factor influencing the effort of some students. These responses signal that a potential constraint on student engagement in learning might be peer pressure or, at least, an ethos of modest effort. This classroom culture factor is worthy of further investigation. It may also be that this is a negative influence for only some students, in which case some targeted intervention may be appropriate.

\section{Stated vocational aspirations as a possible motivating factor}

To gain insight into their vocational aspirations, students were asked to respond to two open items:

What sort of work do you hope you will do when you leave school?

What sort of work do you think you will do when you leave school?

The intention was to compare their aspirations and expectations, and even their awareness of potential vocations, by asking them to indicate the sort of work to which they aspired, and which they expected to do (based on the notion of possible selves described Oyserman, Terry, \& Bybee, 2002).

The assumption was that students with aspirations for particular careers may be more motivated to engage in school. The responses of the students were grouped according to categories determined by the patterns of responses. Table 6 presents the number of students in each of these categories according to the work they hoped would do, as well as the type of work they thought they would do.

Table 6: Employment categories that students hope and think they will achieve

\begin{tabular}{lcc}
\hline & Hope & Think \\
\hline Professional & 138 & 103 \\
Trade & 70 & 66 \\
Defence/Police & 14 & 8 \\
Creative arts & 41 & 27 \\
White collar non professional & 7 & 22 \\
Blue Collar & 3 & 6 \\
Sports & 25 & 23 \\
Don't know & 21 & 58 \\
Total responses & 319 & 313 \\
\hline
\end{tabular}

It can be assumed that an aspiration for a professional career would motivate students to be engaged with school work if they see a connection between current schooling success and further study opportunities. In addition, the aspiration to undertake a trade could well be motivating given the ongoing studies needed for most trades (although students at this level may not be aware of this).

In this case there were some interesting comparisons between subgroups. Double the number of girls, compared with boys, indicated both that they hope and think they will follow a professional careers (Chi squared $=14.0, d f=2, \mathrm{p}<.000)$. There were also differences in the case of reading achievement, with the higher achieving students more likely to hope they would follow a professional career (Chi squared $=12.12, d f=2, \mathrm{p}<.002$ )

The decline in the number of students who think they will pursue a professional career is almost entirely explained by the increase in the "don't know" response. In other words, around $10 \%$ of these students aspire to a professional career but do not know whether they can achieve this.

Given that the students stated there is connection between schooling and vocational opportunity, there is potential for schools to become more aware of students' aspirations and expectations, and 
perhaps for more career education, at least on pathways, and in earlier years than is currently the case.

\section{Responses relating to confidence, increment, opportunity and enjoyment in English, science and mathematics}

In addition to interventions seeking to support aspects of self-regulation generally, we are also working with English, science and mathematics teachers. The responses to a range of items relating to attitudes to core subjects are presented in Table 7.

Table 7: Attitudes to English, science and mathematics $(\mathrm{n}=333)$

\begin{tabular}{lcc}
\hline & Mean & s.d. \\
\hline I feel confident that I can learn most things in English & 5.07 & 1.57 \\
Anyone can be good at English if they put their mind to it & 5.47 & 1.48 \\
Trying hard in English will give me more future job opportunities & 5.87 & 1.32 \\
I am enjoying English at secondary school & 4.16 & 1.81 \\
I feel confident that I can learn most things in science & 4.92 & 1.55 \\
Anyone can be good at science if they put their mind to it & 5.41 & 1.53 \\
Trying hard in science will give me more future job opportunities & 5.09 & 1.65 \\
I am enjoying science at secondary school & 5.00 & 1.81 \\
I feel confident that I can learn most things in mathematics & 5.27 & 1.65 \\
Anyone can be good at mathematics if they put their mind to it & 5.58 & 1.47 \\
Trying hard in mathematics will give me more future job opportunities & 6.16 & 1.27 \\
I am enjoying mathematics at secondary school & 4.59 & 1.84 \\
\hline
\end{tabular}

Other than the responses relating to students' enjoyment in English, which are neutral, and mathematics, which are slightly positive, all other responses are positive, and some, such as those connecting mathematics and English to job opportunities, are very positive. The only significant differences among sub-groups based on achievement are that the higher performing group in both English and mathematics are more confident that they can learn science and mathematics.

Viewed as a whole, these responses indicate that the students have a strong sense of their capacity to achieve success in learning these subjects, and that they recognise the importance of these studies for post-school employment prospects. The scores for student enjoyment of these subjects are lower in each case. Nevertheless, responses suggest that these students are positively motivated towards learning in English, science and mathematics, and there may be benefits in teachers working to enhance the enjoyment of the subjects

\section{Findings and implications}

The questionnaire, the results of which are reported above, was designed to seek information that could inform our interventions that are intended to enhance student engagement and achievement. The overall project seeks to address the apparent disengagement of students from lower socioeconomic groups and students living away from metropolitan areas. We sought insights into the strength and breadth of factors that may influence students' level of engagement. We are drawing on two complementary frameworks: one focusing on the connection between curriculum and engagement; and the other addressing issues associated with social class and culture on student participation. 
The questionnaire identifies a range of responses that indicate a strong positive espousal of purpose and capacity in students' perceptions of their engagement with English, mathematics and science. These include their:

(a) understanding of the importance of mastering key school subjects for later success;

(b) incremental belief in intelligence as amenable to effort rather than a view of fixed abilities; and

(c) view that success at school is influenced by their own efforts.

A key implication is the need to investigate further the extent to which these factors affect students' learning. Some of the directions suggested by these results are for us to:

- assess students' capacities to self-regulate their learning through accurate self-assessment, meaningful goal-setting and planning, and effective review;

- find out if their assumptions about their potential is matched by effective strategies to achieve task completion and accurate monitoring of their work, to see if their claimed confidence in success with schoolwork is justified;

- investigate and develop students' understandings of their motivations and ways to make sense of their current and potential choices as enacted in classroom participation;

- focus on strategies to enable accurate student self-assessment, planning and task management; and - examine in more detail the effect of classroom culture, and find ways to enhance the positive elements of those cultures and minimise any detrimental effects.

A further implication relates to student familiarisation with post-school options, so that they can make stronger links between current effort and its usefulness in the future. Current practice in the three participating schools is that the introduction of career advice and direct experience of workplaces is usually left to later years in secondary school. While there are strong practical and legal reasons for this orientation, there may be advantages for younger students to be given a more explicit understanding of the relationship between school success and post-school choices.

A broader implication of our analysis relates to the strong reminder of the depth of differences between students. While the survey indicates similar patterns of responses across the schools, with few significant differences between boys' and girls' responses, there was a broad diversity in responses across the range of the students. This analysis points to the need for highly targeted efforts to motivate and influence the classroom behaviour of different student cohorts. In other words, not only do teachers need to target support for student learning based on what the individual students know, but also they need to support the development of positive self-regulatory behaviours based on what the individual students believe.

As indicated in Table 1, most students in each of the schools claim to be open to the opportunities that schooling presents and claim to be aware of how to improve. It may be possible for schools to build on these positive factors, and seek to overcome constraints on students realising these opportunities. Teachers can assist by becoming aware of students' orientations to learning, their perceptions of the value of schooling, and their further vocational aspirations, and by finding ways to overcome factors inhibiting disengagement.

At the time of writing, these results are being used to design some interventions in the participating schools, seeking to address some of the issues raised. We are endeavouring to explore aspects of student self-regulation from two perspectives: the types of classroom tasks, and the associated perspectives on curriculum; and various interventions that address self-regulatory behaviours such as cognitive, metacognitive, social, and affective awareness. One example of an intervention is working with English teachers on developing the Year 8 students' capacities to make effective selfassessment of their learning strategies in reading, including a focus on visualization when listening to narrative texts being read aloud. A range of interpretive tasks have been developed that relate to study of visual texts, such as identifying the thoughts and feelings of characters from visual clues. Another example is working with mathematics teachers to explore alternate approaches to teaching mathematics that involve greater student choice in determining both solution type and strategy. A 
further example involves working with teachers to develop a meaningful language of learning with students, utilising a student self-reporting device modelled on a vehicle dashboard, consisting of three typical, recognisable dials, a speedometer, and fuel and temperature gauges, representing effort, energy and affective reaction to classroom tasks. Another example is working with teachers on the ways that factors such as teacher personality, teaching style, and school study (subject) areas intersect with contextual features. These interventions are all seeking to explore the apparent anomalies between the positive student responses to our survey, and the mismatch of those responses with their apparent school engagement.

\section{References}

Ames, C. (1992). Classrooms: Goals structures and student motivation. Journal of Educational Psychology, 84(3), 261-271.

Apple, M. \& Beane, J. (1999). Democratic schools: Lessons from the chalk face. Buckingham: Open University Press.

Australian Curriculum Studies Association (1996). From alienation to engagement: Opportunities for reform in the middle years of schooling, (Vol. 1, 2 \& 3), Canberra: ACSA.

Boekaerts, M. (1998). Coping in context, goal frustration and goal ambivalence in relation to academic and interpersonal goals. In E. Frydenberg (Ed.) Learning to cope: Developing as a person in complex societies (pp. 175-197). Oxford: Oxford University Press.

Boekaerts, M., \& Cascallar, E. (2006). How far have we moved toward integration of theory and practice in self-regulation? Educational Psychology Review, 18, 199-210.

Cumming, J. (1996). From alienation to engagement. Canberra: Australian Curriculum Studies Association.

Delpit, L. (1988). The silenced dialogue: Power and pedagogy in educating other people's children. Harvard Educational Review, 58(3), 280-298.

Desforges, C., \& Cockburn, A. (1987). Understanding the mathematics teacher: A study of practice in first schools. London: The Palmer Press.

Doyle, W. (1986). Classroom organisation and management. In M. C. Wittrock (Ed.), Handbook of research on teaching (pp. 392-431). New York: Macmillan.

Dweck, C. S. (2000). Self theories: Their role in motivation, personality, and development. Philadelphia: Psychology Press.

Elliot, A. J. (1999). Approach and avoidance motivation and achievement goals. Educational Psychologist, 34 (3), 169-189.

Fredericks, J. A., Blumfield, P. C., \& Paris, A.H. (2004). School engagement: potential of the concept, state of the evidence. Review of Educational Research, 74(1), 59-110.

Greene, J., \& Azevedo, R. (2007). A theoretical review of Winne and Hadwin's model of selfregulated learning: New perspectives and directions. Review of Educational Research, 77(3) 334-372.

Hunter, L. (2007). Machinations in the middle. Australian Educational Researcher, 34 (2), 1-6.

Luke, A., Elkins, J., Weir, K., Land, R., Carrington, V., Dole, S., Pendergast, D., Kapitzke C., van Kraayenoord, C., Moni, K., McIntosh, A., Mayer, D., Bahr, M., Hunter, L., Chadbourne, R., Bean, T., Alvermann, D., \& Steven, L. (2003). Beyond the middle: A report about literacy and numeracy development of target group students in the middle years of schooling (Vols $1 \& 2$ ). Brisbane: J. S. McMillan Printing Group.

Main, K., \& Bryer, F. (2007). A framework for research into Australian middle school practice. Australian Educational Researcher, 34(2), 91-105. http://www.aare.edu.au/aer/online/0702f.pdf

Martin, A., \& Marsh, H. (2006). Academic resilience and its psychological and educational correlates: A construct validity approach. Psychology in the Schools, 43(3), 267-281.

Onyx, J, Wood, C. Bullen, P., \& Osburn, L. (2005) Social capital: A rural youth perspective, Youth Studies Australia, 24(4), 21-27. 
Oyserman, D., Terry, K., \& Bybee, D. (2002). A possible selves intervention to enhance school involvement. Journal of Adolescence, 25, 313-326.

Pendergast, D., Flanagan, R., Land, R., Bahr, M., Mitchell, J., Weir, K., Noblett, G., Cain, M., Misich, T., Carrington, V., \& Smith, J. (2005). Developing lifelong learners in the middle years of schooling. Canberra, ACT: Ministerial Council on Education, Employment, Training, and Youth Affairs (MCEETYA) Report.

http://www.mceetya.edu.au/verve/_resources/lifelonglearn_midyears.pdf

Pintrich, P., \& De Groot, E. (1990). Motivational and self-regulated learning components of classroom academic performance. Journal of Educational Psychology, 82, 33-40.

Sullivan, P. A., \& McDonough, A. M. (2007). Eliciting Positive Student Motivation for Learning Mathematics. Mathematics: Essential Research, Essential Practice - (Proceedings of the 30th annual conference of the Mathematics Education Research Group of Australasia (pp. 698707). Adelaide: MERGA.

Sullivan, P., McDonough, A., \& Prain, V. (2005). Student engagement in the Middle Years: Describing influences and possible teacher actions. Proceedings of the Australian Association of Research in Education Annual Conference. Sydney, November. http://www.aare.edu.au/05pap/sul05134.pdf

Sullivan, P., Tobias, S., \& McDonough, A. (2006). Perhaps the decision of some students not to engage in learning mathematics in school is deliberate. Educational Studies in Mathematics, 62(1), 81-99.

Tadich, B., Deed, C., Campbell, C. \& Prain, V. (2007). Student engagement in the middle years: A year 8 case study. Issues in Educational Research, 17, http://www.iier.org.au/iier17/tadich.html

Taylor, J., \& Nelms, L. (2008). Life chances at 16: Life stage study stage 8, Brotherhood of St. Laurence Melbourne.

Zimmermann, B. (2001). Theories of self-regulated learning and academic achievement: An overview and analysis. Mahwah, NJ: Lawrence Erlbaum Associates. 